\title{
Resolución de enigmas geológicos e históricos utilizando técnicas gemológicas avanzadas: Caso del ópalo noble de Franco Dávila (1772)
}

\author{
Solving geological and historical puzzles with advanced \\ gemologic techniques: The Franco Dávila (1772) precious opal \\ case.
}

\author{
J. García-Guinea, J. González-Alcalde, M. Furio, A. Jorge, F. Garrido \\ Museo Nacional de Ciencias Naturales (MNCN, CSIC), Calle José Gutiérrez Abascal 2, Madrid 28006, \\ Email: guinea@mncn.csic.es
}

\section{RESUMEN}

Un gran ópalo noble de 33 gramos engastado en montura de plata dorada está expuesto al público en el Museo Nacional de Ciencias Naturales (MNCN). Esta pieza histórica está documentada en su propia montura (año 1772), en el legajo 775 del Archivo del Museo y en la muestra 395 del Catálogo de muestras de Pedro Franco Dávila. Su patrón de difracción de rayos $X(D R X)$ es muy parecido al de otros ópalos de origen volcánico y contiene cantidades variables de cristobalita, tridimita y sílice amorfa. El espectro Raman muestra una banda con picos a 242, 343 y $416 \mathrm{~cm}^{-1}$ asociados a deformaciones O-Si-O; otra con picos a 780 y $819 \mathrm{~cm}^{-1}$ de vibraciones de tensión simétricas $\mathrm{O}-\mathrm{Si}-\mathrm{O}$ de anillos de 3 y 4 eslabones y otras menores. El espectro Raman es similar a los de ópalos mexicanos de origen volcánico y muestra una banda con nodos de tensión v1 $(\mathrm{OH})$ a $3233,3393,3511,3628 \mathrm{~cm}^{-1}$ relacionados con grupos OH con enlaces de hidrógeno con grupos silanoles aislados. Mediante microscopía dual confocal interferométrica 3D (MCI3D), que es una técnica no destructiva de alta resolución y tecnología LED, se desvela la geometría de grabado del buril sobre la montura mientras que la tomografía computerizada de rayos $\mathrm{X}$ destaca la talla cuadrada de tipo carre-princesa y los rellenos de $\mathrm{AgCl}$ de una fisura. Bajo microscopia electrónica de barrido ambiental (MEBA) se han observado baritinas, filoncillos de sílice enriquecida en Mn y elevados contenidos de Al y K. Estos datos, junto con la información histórica sugieren que la pieza procede de los yacimientos históricos de ópalos encajados en andesitas de Eslovaquia y explican la compleja óptica del cabujón. El marco de $\mathrm{Ag}$ tiene $\mathrm{Hg}$ y $\mathrm{AgCl}$ que indican su extracción por amalgama; además tiene $\mathrm{Ag}_{2} \mathrm{~S}$ que podría provenir de Nueva España, entonces (año 1772) en plena producción de plata. La asociación de varias técnicas analíticas no-destructivas preserva la integridad de esta pieza histórica aportando datos analíticos significativos que permiten deducir procesos genéticos de minerales, procedencias y técnicas de manufactura de materiales. Todo ello facilita la caracterización, interpretación, conservación y valorización del patrimonio cultural y arqueológico.

Palabras clave: Ópalo; Gemología; Colecciones Históricas; Técnicas no destructivas.

Recibido el 30 de marzo de 2016 / Aceptado el 01 de julio de 2016 / Publicado online el 24 de noviembre de 2016

Citation / Cómo citar este artículo: García-Guinea, J. et al., (2016). Resolución de enigmas geológicos e históricos utilizando técnicas gemológicas avanzadas: Caso del ópalo noble de Franco Dávila (1772) . Estudios Geológicos 72(2): e056. http://dx.doi. org/10.3989/egeol.42459.410.

Copyright: () 2016 CSIC. This is an open-access article distributed under the terms of the Creative Commons Attribution-Non Commercial (by-nc) Spain 3.0 License. 


\section{ABSTRACT}

The large precious opal weighting 33 grams fitted in a silver jewel and exposed to visitors at the Museo Nacional de Ciencias Naturales (MNCN) is well documented in: (i) its own mounting (1772), (ii) at the 775 document of the Archive of the MNCN and (iii) the 395 specimen described in the of Pedro Franco Dávila catalogue. The X-ray diffractogram (XRD) performed onto the opal block is very similar to other opals of volcanic origin containing varied amounts of cristobalite, tridymite and amorphous silica. The Raman spectrum shows a band peaked at 242, 343 and $416 \mathrm{~cm}^{-1}$ associated with O-Si-O stretching groups; other spectral band peaked at 780 and $819 \mathrm{~cm}^{-1} \mathrm{corres}^{-}$ ponding to vibration of symmetrical $\mathrm{O}-\mathrm{Si}-\mathrm{O}$ rings of 3 and 4 link members, plus other minor bands. The Raman spectrum is also very similar to those observed in Mexican opals of volcanic origin containing an spectral band of stretching nodes $v 1(\mathrm{OH})$ at $3233,3393,3511,3628 \mathrm{~cm}^{-1}$ related to $\mathrm{OH}$ groups with hydrogen bonds of isolated silanol groups. The interferometric confocal dual microscope 3D (MCI3D), which is a nondestructive facility of high resolution and LED technology reveals the geometry of graver tools on the silver jewel and the computed tomography X-ray highlights the opal cutting as a squared princess type and silver chloride infillings of a crack probably caused by a shock on a corner. Under the scanning electron microscope we observed barite, sealed veins of silica rich in $\mathrm{Mn}$ and opal with high contents of $\mathrm{Al}$ and $\mathrm{K}$ which, along with the historical data, the piece can be attributed to the historical site of opals hosted in Slovakia andesite rocks, this data explains the optical light behavior in the cabochon. The silver jewel has large amounts of $\mathrm{Hg}$ and $\mathrm{AgCl}$ indicating amalgam method. In addition the natural $\mathrm{AgS}_{2}$ phases probably come from Nueva España (year 1772) in full production of silver in such time. The association of new analytical non-destructive techniques combines the preservation of samples together with significant analytical data allowing us to deduce genetic mineral processes, provenances and manufacturing techniques of materials. These facilities allow the characterization, interpretation, conservation and enhancement of cultural and archaeological heritage.

Keywords: opal; gemology; historic collections; Non-destructive techniques.

\section{Introducción}

Los análisis de materiales geológicos y de metales han estado tradicionalmente basados en secciones delgadas, probetas pulidas, difractogramas de rayos $\mathrm{X}(\mathrm{DRX})$ y análisis químicos que requieren necesariamente destruir total o parcialmente la muestra para obtener unos excelentes resultados analíticos. Por otra parte, la Gemología analiza gemas de forma no destructiva, pero sus técnicas tradicionales basadas en medición de índices de refracción, pesos específicos, observación de inclusiones a la lupa binocular, espectroscopia óptica de absorción, medidas de conductividades eléctricas o térmicas, etc., siempre han sufrido problemas de indefiniciones analíticas muy limitantes. Recientemente, los últimos avances en fotónica y los nuevos equipos no destructivos con cámaras analíticas muy amplias permiten analizar piezas valiosas enteras preservando su integridad. Por ejemplo, en 2014 hubo dos premios Nobel de Física a la invención de LEDs azules eficientes basados en nitruro de galio $(\mathrm{GaN})$ y de Química al desarrollo de la microscopía de fluorescencia de elevada resolución (Murali et al., 2015; Meixner, 2016). Este conjunto de nuevas técnicas analíticas no-destructivas está unificando progresivamente dos factores positivos como son la preservación absoluta de la integridad de las muestras junto con significativos avances analíticos que ya permiten inferir mucho mejor sobre procesos genéticos y sobre técnicas de manufactura de materiales. Estas nuevas técnicas de análisis de materiales geológicos están facilitando mucho la caracterización, interpretación, conservación y valorización del patrimonio cultural y arqueológico. Los geólogos conocen bien la gran complejidad de las rocas y de los procesos geológicos y físico-químicos antiguos y recientes que actúan sobre materiales naturales y sobre artefactos arqueológicos que deben ser analizados por técnicas no destructivas (Artioli, 2016). Para el presente estudio analítico, utilizando este tipo de técnicas no destructivas, hemos seleccionado una muestra multicolor de ópalo noble montada en un marco de plata sobredorada con oro de $6 \times 6 \times$ $1 \mathrm{~cm}$ con una inscripción de fecha de manufactura 1772 perteneciente a la colección fundacional del MNCN creada por Pedro Franco Dávila y el Rey Carlos III. Se trata de una pieza de joyería histórica, documentada en el Archivo Histórico del propio Museo (AMNCN) (Franco Davila, 1784), que siempre ha estado expuesta al público pero que nunca ha sido estudiada mediante técnicas tradicionales que podrían alterarla sin aportar información novedosa sobre su ya conocida naturaleza mineral. Sin embargo, usando nuevas técnicas no destructivas del propio $\mathrm{MNCN}$, en el presente estudio se aporta 
nueva información particularmente detallada y difícilmente accesible hace solo una década.

La palabra ópalo procede del Latin ópalus y previamente del Griego ò $\pi \alpha ́ \lambda \lambda$ los (opállios) que significa piedra que cambia de color. Existen muchas citas históricas sobre este material muy apreciado ya por los romanos (Caucia et al., 2013). Llama la atención que en 1845 ya se sugería que los parches de color del ópalo noble eran como pequeños poros ordenados en líneas paralelas de forma tridimensional mostrando una organización cristalina, lo que supone una descripción bastante precisa y cercana a la realidad actual (Brewster, 1845). También es muy importante recordar que en tiempos históricos, los ópalos nobles procedían casi exclusivamente de los yacimientos volcánicos (andesíticos) de Czernowitz, en la actual Eslovaquia. Posteriormente, fueron apareciendo otros afloramientos y en la actualidad casi todos los ópalos nobles del mercado proceden de Australia (Macdonald, 1904; Crettenden et al., 1979; Hsu et al., 2015). En la década de los sesenta, con el uso generalizado de la microscopía electrónica, se observó que los colores del ópalo noble se producían por difracción de la luz en estructuras tridimensionales formadas por paquetes homogéneos de partículas esféricas de sílice de tamaños entre 1500 y $4000 \AA$ de diámetro (Sanders, 1964); por difracción de rayos $\mathrm{X}(\mathrm{DRX})$ se descubrió $\alpha$-cristobalita y sílice amorfa en las esferas (Jones et al., 1964). El mismo grupo australiano propuso una hipótesis genética del ópalo noble que consistía en la precipitación primaria por evaporación de partículas de $400 \AA ̊$ y posterior coalescencia secundaria de agregados coloidales rellenando cavidades de niveles superficiales (Darragh et al., 1966). Estas primeras publicaciones de los años sesenta en la revista Nature sobre ópalo noble australiano fueron revolucionarias y dieron lugar a otras parecidas ampliando diferentes aspectos estructurales y genéticos (Rau \& Amaral, 1969; Sanders \& Murray, 1978; Hachisu \& Yoshimura, 1980). Las fases naturales de sílices hidratadas fueron definidas por DRX (Jones \& Segnit, 1971) estableciéndose ópalo-C (bien ordenada $\alpha$-cristobalita), ópalo-CT ( $\alpha$-cristobalita, $\alpha$-tridimita desordenadas) y ópalo-A (altamente desordenado, casi amorfo). En los últimos años, se han generalizado los estudios de ópalos por espectroscopia Raman buscando diferentes tipos genéticos y diferenciándolos desde el punto de vista molecular de otras variedades de la sílice (Smallwood et al., 1997; Ostrooumov et al., 1999; Ilieva et al., 2007). El ópalo natural tiene proporciones variables de agua, que se puede detectar por espectroscopia Raman (Walrafen et al., 1986; Carey, 1998; Auer \& Skinner, 2008; Sun, 2009). El microscopio electrónico de barrido ambiental (ESEM) operando a bajo vacío realiza la conducción electrónica a través de vapor de agua lo que permite (i) preservar la integridad de los colores la muestra, (ii) la del agua interna de la muestra y (iii) facilitar la salida de catodoluminiscencia del interior del ópalo activada por el haz de electrones. La sonda de química-elemental por energías dispersivas de rayos X (EDS) permite hacer análisis puntuales tanto del ópalo como de la montura polimetálica. Las fases de sílice tienen centros luminiscentes intrínsecos, mayoritariamente asociados a defectos de oxígeno. Sin embargo, también tienen otros centros luminiscentes extrínsecos relacionados con defectos puntuales por inclusión de elementos ajenos, como hierro, manganeso, talio, titanio, uranio, etc. (Alonso et al., 1983; Martini et al., 1995; Krbetschek et al., 1997; Spooner \& Questiaux, 2000; Götze et al., 2001). Los mapas de catodoluminiscencia pancromática señalan las anomalías luminiscentes del ópalo y la tomografía computerizada de alta resolución por rayos X (TCRX) resalta diferencias de densidades, pudiendo apreciar la ubicación del cloruro de plata que rellena algunas fisuras y la propia superficie-aire que permite hacer modelos 3D de la pieza destacando muy bien las facetas del tallado (Wellington \& Vinegar, 1987; Ketcham \& Carlson, 2001). Finalmente, el microscopio confocal-perfilométrico permite realizar estudios de superficies en 3D en color real y obtener perfiles de muy alta resolución, que en nuestro caso, hemos aplicado a la montura metálica para observar detalles del proceso de grabado a punzón. La perfilometría de precisión tiene múltiples aplicaciones geológicas (Belem et al., 2000; Lee et al., 2001; Kita et al., 2009). Se ha estudiado el broche de ópalo-plata de Franco Dávila, por documentación histórica original, por DRX, ESEM-EDX-CL, Raman, TCRX y por MCI3D lo que ha permitido sacar conclusiones sobre el origen de los materiales (ópalo y plata) y sobre algunos procesos de manufactura de la pieza de joyería. Este trabajo es una 
muestra representativa de un modelo de estudio de una pieza de joyería histórica, con metales y gemas, realizado con técnicas no-destructivas modernas más avanzadas que las tradicionales rutas analíticas gemológicas.

\section{Técnicas analíticas no destructivas y muestras históricas}

\section{Documentación Histórica y ubicación actual del Ópalo Noble de Franco Dávila}

El Archivo del Museo Nacional de Ciencias Naturales (AMNCN) custodia sus documentos desde su fecha de fundación en 1771. Entre ellos, destaca una colección de legajos manuscritos históricos que relatan la propia historia del centro junto con la de muchos personajes históricos relacionados con el Museo y las Ciencias de la Naturaleza. Para localizar legajos se pueden utilizar los catálogos de documentos publicados por María Ángeles Calatayud Arinero, quien fuera archivera del (AMNCN) durante muchos años. De esa forma, pudimos encontrar el legajo del Ópalo Noble de Franco Dávila (Calatayud-Arinero, 1987). Por otra parte, la pieza de Ópalo Noble de Franco Dávila se encuentra expuesta al público en la vitrina de esmeraldas y oros de Colombia, en la Sala de Mineralogía del MNCN.

\section{Difracción de rayos $X$}

La identificación mineralógica de la placa de ópalo fue realizada por DRX en un difractómetro de X'Pert MPD usando radiación $\mathrm{CuK} \alpha$ de 1.540598 de $3^{\circ}$ a $63^{\circ} 2 \theta$, operando a $45 \mathrm{kV}$ y $40 \mathrm{~mA}$ con un salto de $0.00302 \theta$ y 2000 puntos de registro. Para ello, se desmontó el porta-muestras para poder alojar la piedra de ópalo de $5 \times 5 \times 0.5 \mathrm{~cm}$. Con el fin de preservar la integridad de la pieza, no se difractó muestra en polvo, pero el espectro de DRX se considera representativo por la gran cantidad de cristales desorientados de cristobalita y tridimita contenidos en las lepisferas de ópalo. La determinación del grado de orden/desorden de la sílice del ópalo de Franco Dávila se realizó utilizando anchura del pico de difracción a $\sim 0.4$ nm justo en el punto medio de su altura. Para ello se siguió el método de Smith $(1997,1998)$ sometiendo a la curva experimental de DRX a un suavizado automático utilizando software Origin 6.0. La curva y la línea base fueron ajustadas manualmente para poder determinar la intensidad máxima, la intensidad media de la máxima, y su correspondiente anchura media.

\section{Microscopio Electrónico de Barrido con catodoluminiscencia}

Se realizaron análisis morfológicos y determinaciones de la composición química elemental, tanto de la pieza de ópalo como de su montura polimetálica. Para ello, se empleó un equipo de MEBA de marca FEI Inspect operando en condiciones de bajo vacío (80 pascales) y $20 \mathrm{kV}$ y $60 \mu \mathrm{A}$ de corriente de emisión. Estas condiciones de baja potencia permiten proteger la muestra y hacer análisis químicos por espectrometría de energías dispersivas de rayos $\mathrm{X}$ (EDX) en muestras no conductoras a los electrones, es decir, muestras aislantes sin metalizar. El equipo tiene sonda de electrones retro-dispersados (ERD) y un espectrómetro de energías dispersivas de rayos $\mathrm{X}$ (EDX). También dispone de una sonda de catodoluminiscencia (CL) espectral MONOCL3 de Oxford Instruments que permite registrar espectros y mapas luminiscentes.

\section{Espectroscopia Raman con rejilla espectral extendida}

El espectro Raman de 100 a $5000 \mathrm{~cm}^{-1}$ de la muestra de ópalo noble fue registrado en el microscopio Thermo-Fischer DXR Raman-PL utilizando un objetivo 100X del microscopio confocal junto con la fuente láser a $532 \mathrm{~nm}$ operando a $10 \mathrm{~mW}$. El sistema funciona con software OMNIC 1.0 ajustado a las condiciones habituales de trabajo, como apertura de haz de 25 micras, tiempo de blanqueo de $30 \mathrm{~s}$ y un promedio de cuatro exposiciones programadas de 10 s cada una.

\section{Tomografía computerizada de rayos $X$ de alta resolución}

El cabujón de ópalo de Dávila fue montado en un molde de poliestireno transparente a los Rayos X para ser analizado en un TCRX Nikon XT H-160 durante 3 horas. Se registró una serie de 1583 radiografías 
de 1.985 Kbytes cada una de ellas tomadas consecutivamente durante el giro de $360^{\circ}$ de la muestra sobre sí misma. El equipo permite generar rayos $\mathrm{X}$ con un ánodo multi-target de diferentes metales y posee un variador de potencia que permite regular la energía e intensidad de los rayos $\mathrm{X}$ dependiendo de la densidad de la muestra objeto de estudio. En nuestro caso, se generaron los rayos $\mathrm{X}$ a $117 \mathrm{kV}$ y $41 \mu \mathrm{A}$, utilizando el target de $\mathrm{W}$ y un filtro de 0.125 $\mathrm{mm}$ de $\mathrm{Cu}$ con el fin de atenuar los rayos $\mathrm{X}$ blandos. El software utilizado fue el VG Studio Max 2.2, el cual permite hacer reconstrucciones $3 \mathrm{D}$ ultrarrápidas obteniéndose formas externas del sólido de muy alta resolución e imágenes del interior de la muestra correspondientes a la distribución de las inclusiones de otros compuestos de densidades diferentes como metales o aire.

\section{Microscopia dual confocal perfilométrica 3D de alta resolución con tecnología LED}

Los análisis de perfilometría y fotografías confocales 3D de la montura de plata fueron realizadas en un microscopio confocal interferométrico 3D Leica DCM8 de luz blanca. El equipo MCI3D utiliza cuatro fuentes de luz LED - azul $(460 \mathrm{~nm})$, verde (530 $\mathrm{nm})$, rojo $(630 \mathrm{~nm})$ y blanca $(\sim 550 \mathrm{~nm})$. Dispone de una cámara integrada para captar imágenes reales en color con un amplio campo de visión. También tiene de un sistema XY topográfico automático que permite realizar un mosaico, es decir, que empalma sucesivas tomas generando una imagen unificada de un área grande. El software facilita los análisis de imágenes en $3 \mathrm{D}, 2 \mathrm{D}$, tanto en blanco y negro como en color.

\section{Resultados y discusión}

\section{Documentación Histórica Escrita}

\section{En la montura de la pieza}

La pieza joyera objeto de estudio es una caja metálica dorada con un ópalo iridiscente. El ópalo está montado en un soporte de plata y oro rodeado con cadenas de bolas soldadas, rematado por un lazo también de plata sobredorada. Sus dimensiones aproximadas son $6,5 \times 6,5 \mathrm{~cm}$ (con montura) y $5 \mathrm{x}$ $5 \times 0.5 \mathrm{~cm}$ el cabujón de ópalo suelto (Fig. 1). Sus

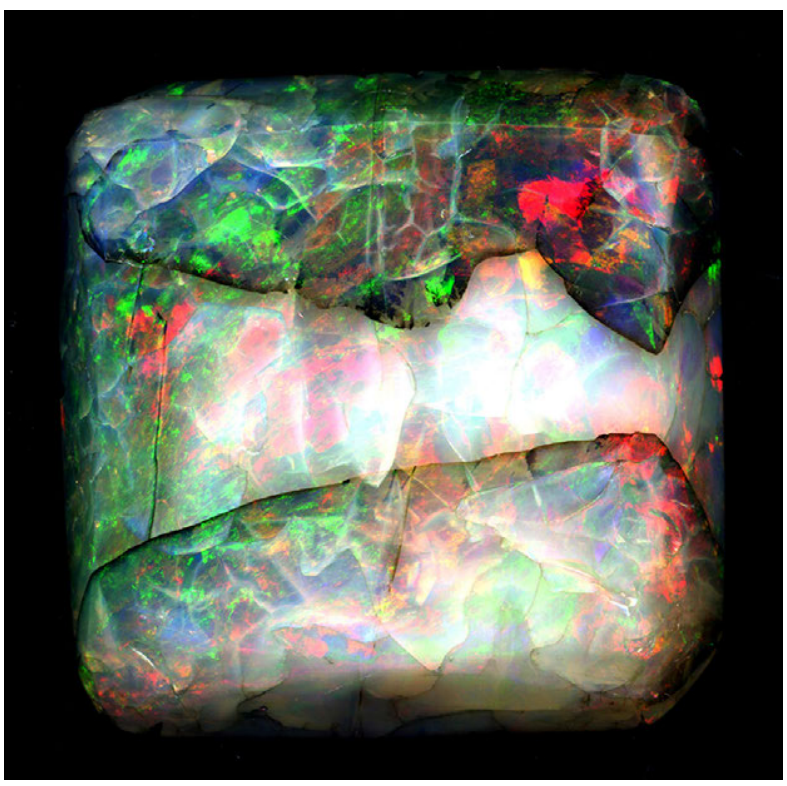

Fig. 1.-Ópalo noble tallado de 33 gramos traído a España por Pedro Franco Davila en 1772 y procedente de las minas de ópalo de Dubnik (Eslovaquia). Las líneas oscuras son filones hidrotermales sellados de sílice-manganeso.

pesos son de $33.2 \mathrm{~g}$ el ópalo y de $70.7 \mathrm{~g}$ el marco de plata. La montura de esta piedra fue realizada en París en 1772, por el artista Henri Bodson. La pieza procede de la colección de D. Pedro Franco Dávila, fundacional del MNCN.

\section{En el Legajo N775 del Archivo del Museo}

En el copiador de cartas, $n^{\circ} .18$, de Franco Dávila, se recoge una carta (Fig. 2 a y b) (Calatayud, 1987: n $^{\circ}$. 775, pág. 277), de fecha 7 de agosto de 1784 por la cual, Franco Dávila se dirige a Monsieur Boytet, cónsul general de Francia. En la carta se explica que Monsieur Bodson había guarnecido, es decir, engastado una pieza ópala en plata dorada con un círculo de oro. Por ese trabajo le exigía quince luises de oro, cantidad que considera exorbitante, puesto que otros habrían hecho ese trabajo por diez doblones como máximo. A esta exigencia argumenta Franco Dávila que no le debe ningún dinero a Monsieur Bodson, al parecer porque ya se lo había abonado, como a todos los demás con los que tenía deudas. Dice que está tan lejos de deberle dinero como lo está el Tamoxlán de Persia (sic). Franco Dávila le indica a Monsieur Boytet que se haga cargo de exponerle a Monsieur Bodson sus razones y añade que le pague aquello que le parezca justo 
(a)

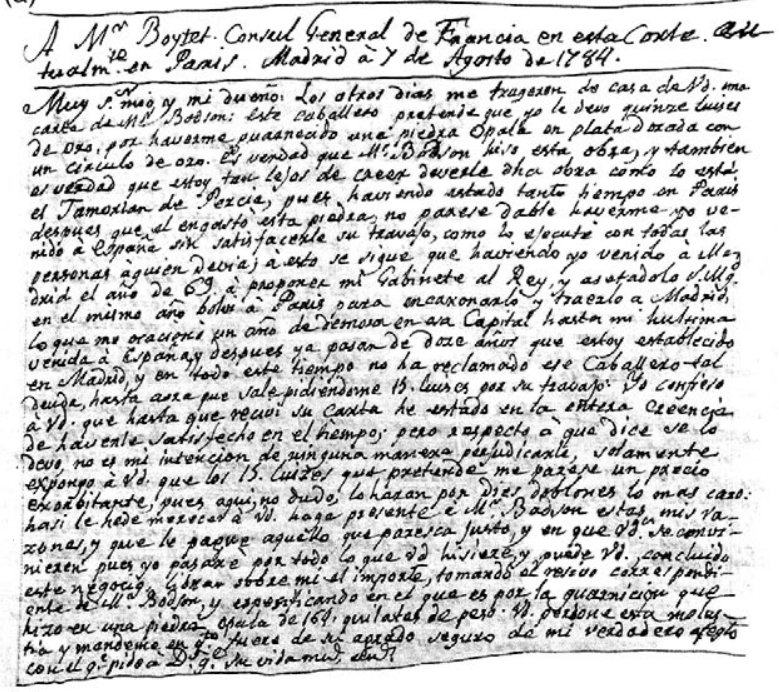

(b)

A $M^{N}$ Boyter Consul Genexd ae Fancia en estal coote actwalm.

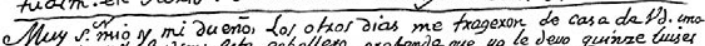

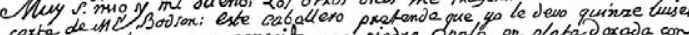

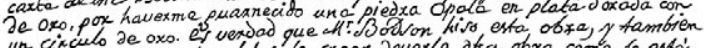

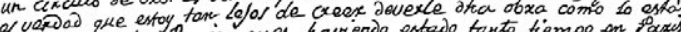

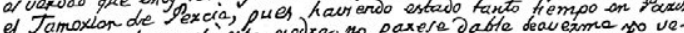

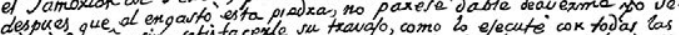

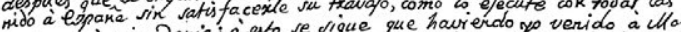

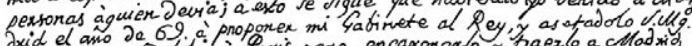
en el mismo ano boti 'a' Paris para encaxonaxlo y traexlo a CMadxio lo que me ocasionio un año de remara en daze anios que estoy establecido vexida a espoña,y despues ya yes an do ha reclamado ele caballexo tol

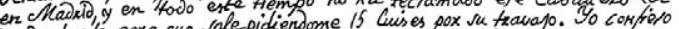
juda, hasta aoxa que vale pidiendome he estado en la entexa cxeencia a'vo. que hasta que ris en el tiempo. pexo xespecto a' que dice ve lo de havex intexcion de xin quna manexa pexfudicaxle, solam exte

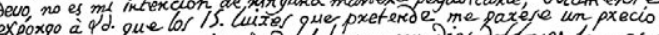
expoxpo a tarte, pues aqui, no drde, lo haxan pox jies Jobloxes to mas caxo

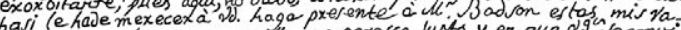
hasi lity que le paque aquello que paxerca justo, y en que 9 g. de convi: ziexen pues yo pas abe pox todo lo que 92 hisiaxe y puede 2\%. concluido esfe negorio. cibxax sobxe mi al impoxte, tomaxdo el nesivo coxxes pon riente de ill." sodfix ly espesiticando er el gue es pox a quaxricion que hizo er una piedra topala je 164 quilates de peso. is. pexdore esta noles

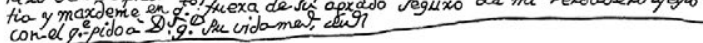

Fig. 2a.-Legajo 775 del AMNCN fechado en 1784 de Pedro Franco Dávila hacia Monsieur Boytet sobre un ópalo engastado en plata.

Fig. 2b.-El mismo Legajo 775 del AMNCN después de sufrir un proceso artístico-digital de reconocimiento óptico de caracteres para facilitar la lectura del texto respetando al máximo su contenido, grafismo, geometría y estructura.

y se ofrece a aceptar la resolución del cónsul general de Francia y que libre sobre él, es decir, sobre Dávila, el importe. Añade que ese pago es por la guarnición hecha sobre una pieza de ópalo de 164 quilates de peso. Fue Dávila quien trae a Madrid esa pieza para que forme parte del Real Gabinete de Historia Natural. En la actualidad, este ópalo pertenece a la colección permanente del Museo Nacional de Ciencias Naturales y a su exposición permanente en la sección de Geología.
En el Catalogo de muestras entregadas al Museo por Pedro Franco Davila

Muestra: VI. OPALES. 395. Literalmente pone lo siguiente: "Une rare et magnifique Opale orientale, du poids de cent foixante quatre carats, taillée en table quarrée, dont les côtés ont un pouce \& demi de longueur fur un demi-pouce d'épaiffeur. Elle réfléchit toutes les couleurs de l'Arc-en-ciel par grands faifceaux de rayons, $\&$ d' un éclat très-vif. Le Banquier Anglois, de qui nous la tenons, nous a affurés que cette pierre étoit à la ceinture du grand Mogol Mahamet - Schah, lorsque ce Prince fut détroné par Thamas Kouli-kan".

Este párrafo está totalmente vinculado a la pieza por el peso descrito $164 / 5=33$ gramos, ya que un quilate (carat) es la quinta parte del gramo si bien en aquellos tiempos se utilizaba una semilla de algarroba de peso aproximado 0.2 gramos con la inexactitud natural de los métodos de medida de la época. La descripción de la talla carré (quarrée) también corresponde perfectamente con una forma cuadrada. Los colores del arco iris a un ópalo noble, etc... Respecto a su procedencia oriental, no se puede descartar Eslovaquia por su posición geográfica al este de París. En lo referente a la hebilla del Gran Mogol, posiblemente pueda relacionarse mejor con una argucia comercial del vendedor de joyería.

\section{Difracción de rayos $X$}

La Fig. 3 muestra la metodología utilizada para ajustar la pieza de ópalo de 5 × 5 x $0.5 \mathrm{~cm}$ al portamuestras del difractómetro desmontando y retirando el soporte utilizado habitualmente. Las dimensiones del cabujón de ópalo han permitido ajustarlo en el equipo disponible (Fig. 3 a y b). En este caso, no procede difractar mono-cristales mono-bloque obteniéndose escasos picos porque se trata de una roca natural con lepisferas de cristobalita-tridimita dispuestas según todas las orientaciones del espacio. La escasez de picos y el perfil escasamente cristalino del difractograma (Fig. 3c) es atribuible solo a sus componentes de sílice y de agua. La determinación semicuantitativa de la mineralogía (software XPowder, Martin-Ramos) indica la presencia de sílice amorfa, cristobalita y tridimita. El grado de orden/desorden estructural viene expresado por la diferencia entre 


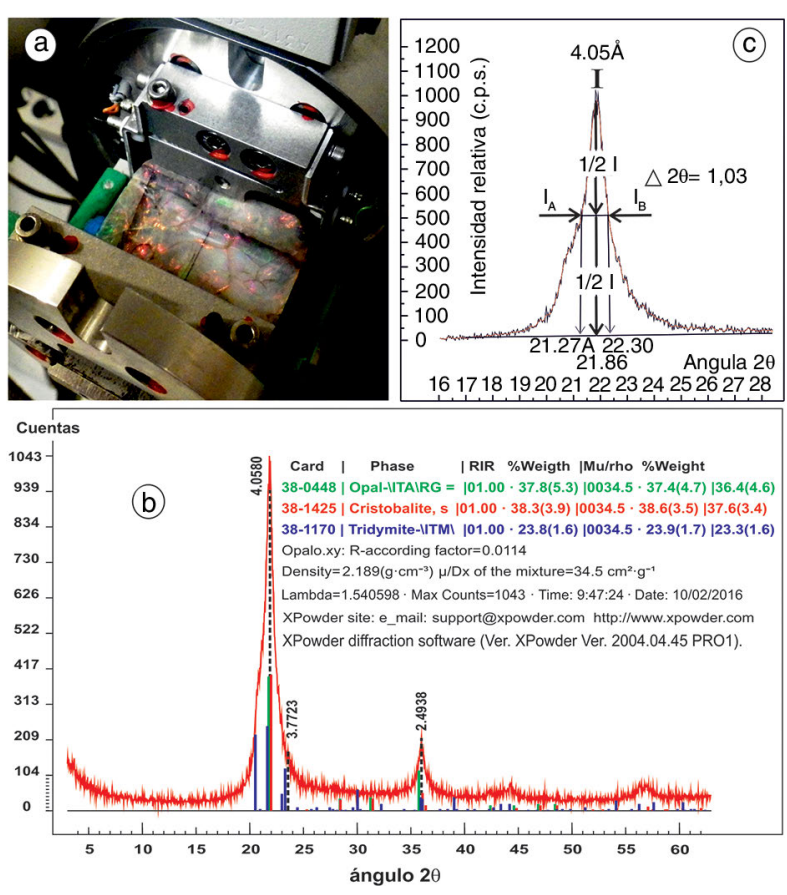

Fig. 3.-Difractograma de Rayos $X$ realizado sobre el bloque de ópalo mostrando fases de tridimita, cristobalita y ópalo amorfo.

las posiciones de las intensidades medias (Fig. 3c). De acuerdo con Smallwood et al., (2008), el difractograma del ópalo noble de Dávila sería de origen volcánico. Algunos trabajos sobre ópalos de Eslovaquia proporcionan patrones de difracción cercanos a los tipos de ópalo C-T (Rondeau et al., 2004), mientras que otras publicaciones también encuentran tipos de opalos-A (Caucia et al., 2013).

\section{Microscopio Electrónico de Barrido Ambiental con sondas de energías dispersivas y de catodoluminiscencia (ESEM-EDS-CL)}

El ópalo y su montura polimetálica (Fig. 4a) pudieron ser estudiados por microscopía electrónica ambiental ESEM, obviamente sin metalizar y a bajo voltaje para proteger la integridad de la pieza. En el caso del ópalo de Dávila, este sistema de operación dificulta la observación de organización de lepisferas y los espectros de catodoluminiscencia son muy poco luminosos por la falta de potencia electrónica, por el agua de la muestra y por la elevada proporción de fases amorfas. La Fig. 4a muestra la pieza joyera estudiada. El marco rojo indica la zona de trabajo que incluye una pequeña vena hidrotermal oscura bien sellada,
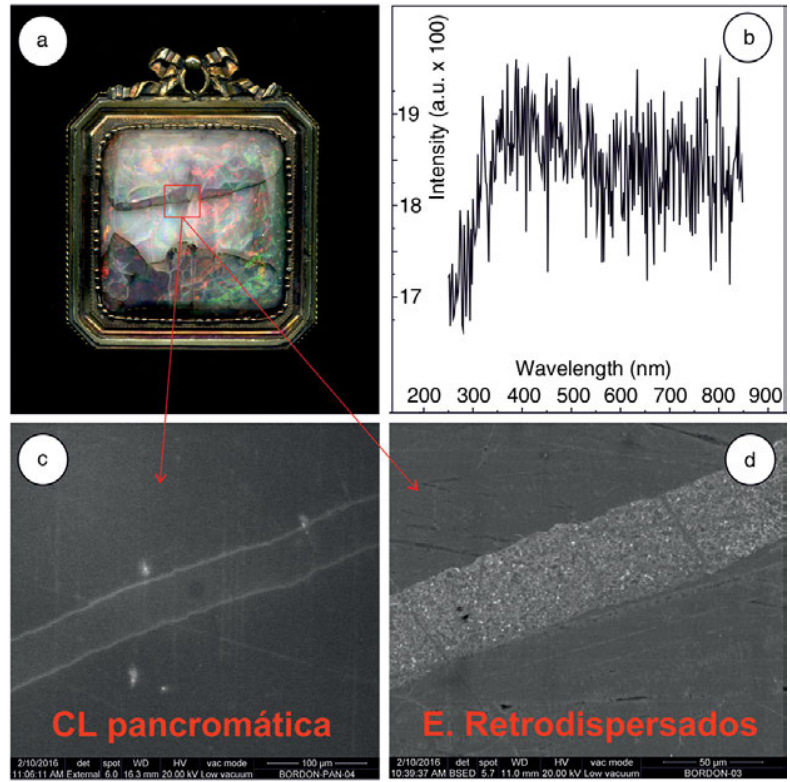

Fig. 4.-Estudio de la joya dentro de la cámara del microscopio electrónico de barrido ambiental: (a) zona de estudio, (b) espectro de catodoluminiscencia, (c) imagen de catodoluminiscencia pancromática de la fisura de sílice-manganeso, (d) imagen de la fisura sílice-manganeso bajo electrones retro-dispersados.

se trata de ópalo marrón-oscuro teñido por óxidos de manganeso.

La Fig. 4b muestra un espectro de CL representativo del ópalo donde destaca un pico en la región UV hacia los $274 \mathrm{~nm}$ y otro hacia los $320 \mathrm{~nm}$ correspondientes muy probablemente a defectos cristalinos de oxigeno producidos por la pérdida de grupos hidroxilos bajo el haz de electrones que estimulan la emisión catodoluminiscente (Jones \& Embree, 1976; Rink et al., 1993). El pico de máxima emisión catodoluminiscente a $387 \mathrm{~nm}$ podría corresponder a defectos del tipo $\left[\mathrm{AlO}_{4} / \mathrm{M}^{+}\right]$(Rink et al., 1993 , Martini et al., 1995) y estar relacionado con las contenidos elevados de Al y K que muestran los resultados de los químico-elementales EDS en el ópalo de Dávila (Tabla 1). Los picos máximos en las regiones espectrales catodoluminiscentes hacia los 410-420 $\mathrm{nm}$ y $450-470 \mathrm{~nm}$ son emisiones intrínsecas de las fases de sílice ampliamente descritas en la bibliografía (Itoh et al., 1988; Kalceff \& Phillips, 1995; Gorton et al., 1997; Stevens-Kalceff, 2009; StevensKalceff, 2013). Desde el punto de vista luminiscente, resulta especialmente interesante la peineta espectral a 496, 505, $513 \mathrm{~nm}$ con una geometría idéntica a la producida por la presencia de grupos uranilos 
asociados a sílice (Garcia-Guinea et al., 2013); este detalle espectral es razonable desde el punto de vista genético de un ópalo hidrotermal y está respaldado por el contenido de uranio en el ópalo (Tabla 1). Finalmente, en la región espectral del rojo-infrarrojo se observa un máximo poco intenso hacia los 634 $\mathrm{nm}$ asimilable a vacantes de oxígenos no enlazados con grupos precursores hidroxilos bajo irradiación catodoluminiscente (Sigel Jr \& Marrone, 1981; Luff \& Townsend, 1990; Remon et al., 1992; Götze et al., 2001). En resumen, se trata de un espectro de CL poco intenso por sus características intrínsecas,

Tabla 1a.-Análisis químicos elementales puntuales por energías dispersivas de rayos $X$

\begin{tabular}{lcccc}
\hline & Opal01 & Opalo2 & Opalo3 & OpalO4 \\
\cline { 2 - 5 } EDS & $(\%)$ & $(\%)$ & $(\%)$ & $(\%)$ \\
\hline U M & -- & -- & -- & 0.15 \\
Al K & 0.58 & 0.42 & 0.55 & 0.65 \\
Si K & 44.13 & 46.17 & 38.53 & 38.52 \\
CI K & 0.41 & -- & 1.28 & 0.89 \\
K K & 0.38 & 0.35 & 0.50 & 0.41 \\
Ti K & 0.12 & -- & -- & \\
Mn K & 1.54 & -- & -- & 0.25 \\
Ba L & -- & -- & 3.59 & 4.20 \\
S K & -- & -- & 1.13 & 1.17 \\
Ag L & 1.04 & -- & 7.29 & 6.72 \\
O & 51.56 & 53.05 & 47.14 & 47.28 \\
Totales & 100.00 & 100.00 & 100.00 & 100.00 \\
\hline
\end{tabular}

y por operar el microscopio electrónico a baja potencia para proteger los colores de la muestra. El espectro muestra emisiones intrínsecas de sílice junto con algunos grupos uranilos extrínsecos, lo que se ajusta con la formación de ópalo en venas hidrotermales asociadas a procesos volcánicos.

En la Fig. 4 se incluyen mapas de detalle pancromáticos de CL (Fig. 4c) y de electrones retrodispersados (Fig. 4d) de una vena hidrotermal micrométrica de ópalo de color marrón oscuro teñido por óxidos de manganeso. Los colores más claros (Fig. 3d) corresponden a masas irregulares de óxidos de manganeso con mayores pesos atómicos destacando sobre el resto de la sílice, lo que explica el color oscuro de la vena oscura sellada siendo una observación frecuente en masas de andesitas volcánicas, por ejemplo dentro de la corta Alpedroches (Atienza, Guadalajara). La Fig. 4c muestra puntos blancos muy luminiscentes correspondientes a pequeños cristales de baritina $\left(\mathrm{BaSO}_{4}\right)$ dentro de la masa de ópalo, junto a dos bandas blancas delimitando perfectamente la vena hidrotermal de sílice-manganeso. Las masas de manganeso son menos luminiscentes que la sílice y apantallan la emisión catodoluminiscente interna del ópalo que termina aflorando la luz justo al llegar a la barrera de manganeso. Es decir, las estructuras laminares de lepisferas de ópalo CT conducen las emisiones catodoluminiscentes hasta al punto de apantallamiento de las masas de oxo-hidróxidos

Tabla 1b.-Análisis químicos elementales puntuales por energías dispersivas de rayos $\mathbf{X}$

\begin{tabular}{|c|c|c|c|c|c|c|c|c|c|}
\hline & CAJA4 & CAJA5 & CAJA11 & CAJA7 & CAJA2 & CAJA13 & CAJA1 & CAJA3 & CAJA8 \\
\hline & $\mathrm{Ag} 2 \mathrm{~S}$ & Ag2S & AgS2 & $\mathrm{AgCl} 2$ & $\mathrm{Ag}, \mathrm{Cu}$ & $\mathrm{Ag}, \mathrm{Au}, \mathrm{Cu}$ & $\mathrm{Au}, \mathrm{Ag}$ & $\mathrm{Au}, \mathrm{Ag}$ & $\mathrm{Au}, \mathrm{Ag}, \mathrm{Cu}$ \\
\hline EDS & $(\%)$ & $(\%)$ & $(\%)$ & $(\%)$ & $(\%)$ & $(\%)$ & $(\%)$ & $(\%)$ & $(\%)$ \\
\hline $\mathrm{Ag} \mathrm{L}$ & 62.80 & 71.24 & 50.49 & 44.58 & 88.46 & 81.14 & 7.53 & 11.39 & 27.35 \\
\hline $\mathrm{Au} \mathrm{M}$ & 23.02 & 9.61 & 29.94 & 23.03 & 1.24 & 9.16 & 83.20 & 81.35 & 57.46 \\
\hline $\mathrm{Hg} \mathrm{M}$ & & & 2.63 & & 2.80 & 0.88 & 9.27 & 6.42 & 6.96 \\
\hline $\mathrm{Cl} \mathrm{K}$ & & & 3.84 & 32.40 & 0.75 & 0.90 & & & 2.02 \\
\hline Cu K & & & 1.80 & & 3.39 & 3.50 & & 0.83 & 4.47 \\
\hline U M & & 3.68 & 2.40 & & 3.36 & 3.49 & & & \\
\hline SK & 14.18 & 15.46 & 6.60 & & & 0.33 & & & \\
\hline Al K & & & 1.13 & & & & & & 0.80 \\
\hline Si K & & & 0.85 & & & & & & 0.95 \\
\hline Fe K & & & 0.33 & & & & & & \\
\hline $\mathrm{Zn} \mathrm{K}$ & & & & & & 0.61 & & & \\
\hline Totales & 100.00 & 100.00 & 100.00 & 100.00 & 100.00 & 100.00 & 100.00 & 100.00 & 100.00 \\
\hline
\end{tabular}


de sílice y manganeso saliendo finalmente al exterior. Las baritinas están frecuentemente asociadas a venas hidrotermales de sílice en cualquier volcanismo andesítico, como los de Eslovaquia o Atienza.

Algunas foto-micro-grafías de la Fig. 5 fueron realizadas sobre la montura polimetálica del cabujón de ópalo alojada dentro de la cámara ambiental ESEM operando a bajo vacío con la conducción electrónica establecida mediante vapor de agua. La sonda EDS permite determinar porcentajes de metales en aleaciones (Tabla 1). La Fig.5a corresponde a unas fisuras del ópalo rellenas de cloruro de plata, probablemente procedentes de la propia montura, como resultado de algún proceso de contaminación durante el lavado de la pieza o el proceso de engaste en plata. La Fig. 5b muestra una soldadura por granulación con composición química bajo EDS de $\mathrm{Cu} 4 \%$, Ag 27\%, Au 57\%, $\mathrm{Hg} 7 \%$ es decir, con más $\mathrm{Cu}$ que el cordón de Au soldado (Tabla 1). Existen trabajos científicos realizados sobre joyas prehistóricas que muestran soldaduras de granulación realizadas en tiempos pasados pero no explican en detalle sus causas (Demortier et al., 1999; Tamla \& Varkki, 2009). Las granulaciones aparecen automáticamente en soldaduras de $\mathrm{Au}$ y Ag utilizando micro-fragmentos (pallones) de una aleación de menor punto de fusión que la masa de plata principal. Esto facilita la soldadura y es práctica habitual en joyería (Cagnetti, 2009). Los pallones de soldadura pueden ser trozos iguales simplemente cortando trozos de un hilo metálico ya que después la forma esférica aparece bajo el fuego por la elevada tensión superficial de estos metales en estado de fusión. Es decir, se trata de una práctica sencilla y actual cuando se pretende mostrar una superficie llena de bolas, además de realizar la soldadura. La Fig. 5c muestra diversos detalles: (i) una esquina de la caja con

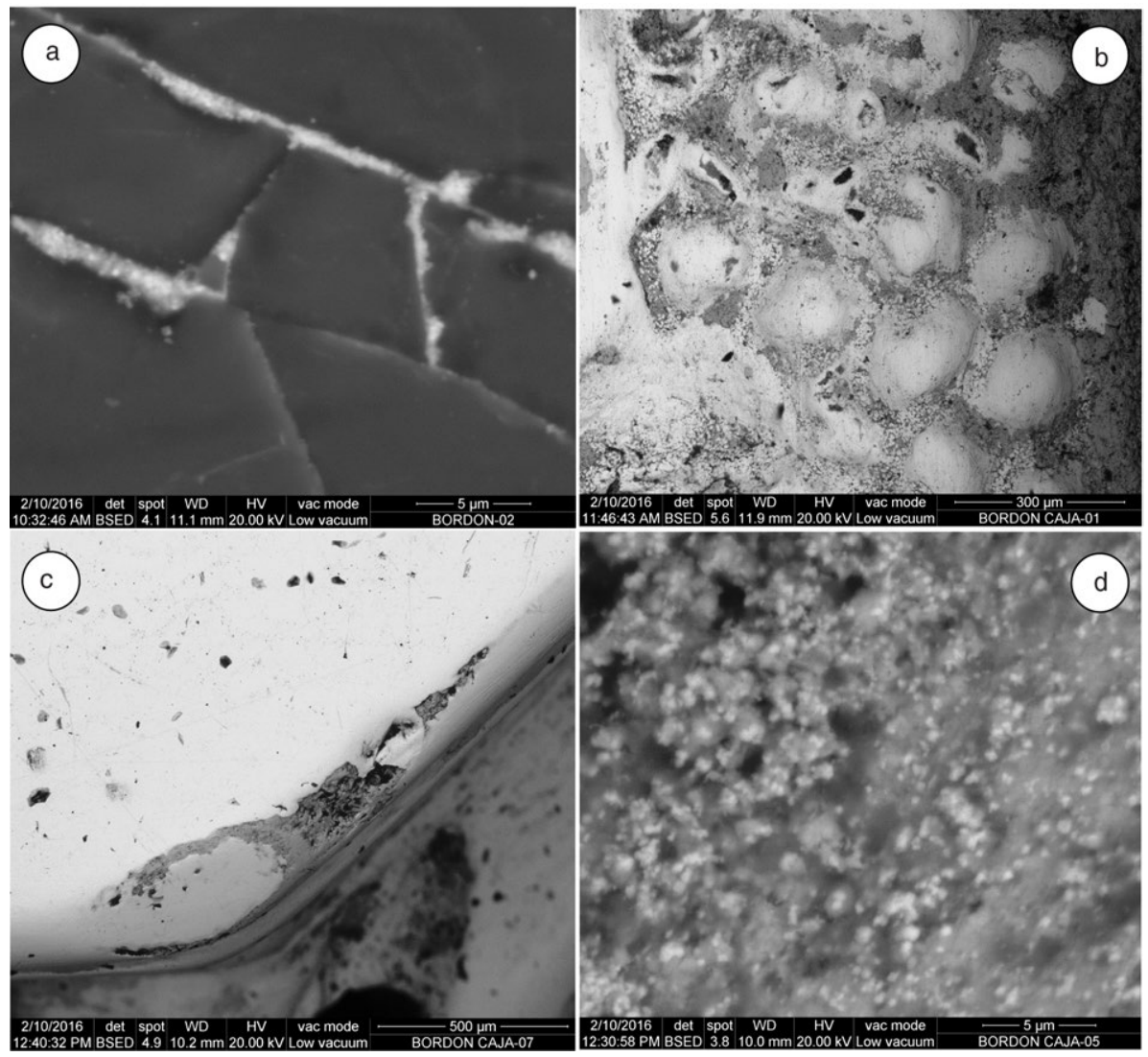

Fig. 5.-Observación de la joya bajo el microscopio electrónico de barrido ambiental: (a) fisuras del ópalo rellenas de cloruro de plata, (b) pallones de soldadura de plata fundidos en bolas, (c) abolladura de una esquina de la montura mostrando oro y el interior de plata. 
una abolladura probablemente debida un simple golpe contra el suelo, (ii) una capa superficial fina de $\mathrm{Au}$ con $\mathrm{Hg}$ que le imprime un color amarillo a la pieza y la protege de la oxidación y (iii) Ag rugosa debajo del desconchón. El Au aparece blanco por su mayor peso atómico que la Ag. La abolladura externa en la caja metálica coincide con un fuerte golpe en una esquina del cabujón de ópalo que le ha producido fisuras y fragmentación localizada solo en la esquina. La foto $5 \mathrm{~d}$ está tomada del interior de la caja de plata y muestra granulaciones e irregularidades de una plata que contiene $\mathrm{Au}, \mathrm{U}, \mathrm{Hg}$, cloruro de plata y sulfuro de plata inferidos desde la analítica EDS (Tabla 1). Este cóctel composicional tiene (ver Tabla 1): (i) componentes residuales de la mineralización original de plata como la acantita $\left(\mathrm{Ag}_{2} \mathrm{~S}\right)$ de Zacatecas o Guanajuato (Chutas \& Sack, 2004; Canet et al., 2009; Moncada et al., 2012; Mango et al., 2014) (ii) componentes residuales del proceso de extracción metalúrgica, como el mercurio y el cloruro de plata por el proceso de amalgama mercurial según el método del patio seguido en aquel entonces en los virreinatos de Nueva España o de Perú en sus momentos de máxima producción histórica hacia 1772 que es la fecha de manufactura de la montura del ópalo (Fisher, 1977) (Ponzio de Léon, 1998; RamosArroyo, Prol-Ledesma et al., 2004; Dobado \& Marrero, 2011), y (iii) componentes añadidos durante el proceso de creación de la manufactura joyera, por ejemplo, el propio oro.

\section{Espectroscopia Raman con rejilla espectral extendida}

La espectroscopia Raman es muy sensible a variaciones moleculares y de contenidos de agua, por lo que se trata de un método analítico no destructivo para clasificar ópalos, quizás más útil que la propia difracción de rayos $\mathrm{X}$, sobre todo cuando están tallados y montados en joyas. Las Fig. 6 a y b representan dos espectros Raman del ópalo noble de Franco Dávila en diferentes rangos de longitudes de onda, uno de 100 a $3400 \mathrm{~cm}^{-1}$ y otro con rejilla espectral extendida de 2600 a $5400 \mathrm{~cm}^{-1}$. En la región espectral de bajas frecuencias aparece la banda intensa correspondiente a deformaciones O-Si-O característica de silicatos con picos a 242, 343 y $416 \mathrm{~cm}^{-1}$; otra banda espectral con picos a 780 y $819 \mathrm{~cm}^{-1}$ se corresponden con vibraciones de tensión simétricas O-Si-O de anillos de 3 y 4 eslabones más otras bandas menores con máximos hacia los $959 \mathrm{~cm}^{-1}$ de vibración de tensión $\mathrm{Si}-\mathrm{O}$ y $1077 \mathrm{~cm}^{-1}$ atribuible a vibraciones de tensión simétricas O-Si-O de anillos de 3 y 4 eslabones. (Walrafen et al., 1986; Carey, 1998; Auer \& Skinner, 2008; Sun, 2009) Comparando este espectro con otros de la bibliografía (Smallwood et al., 1997) (Ostrooumov et al., 1999), observamos que
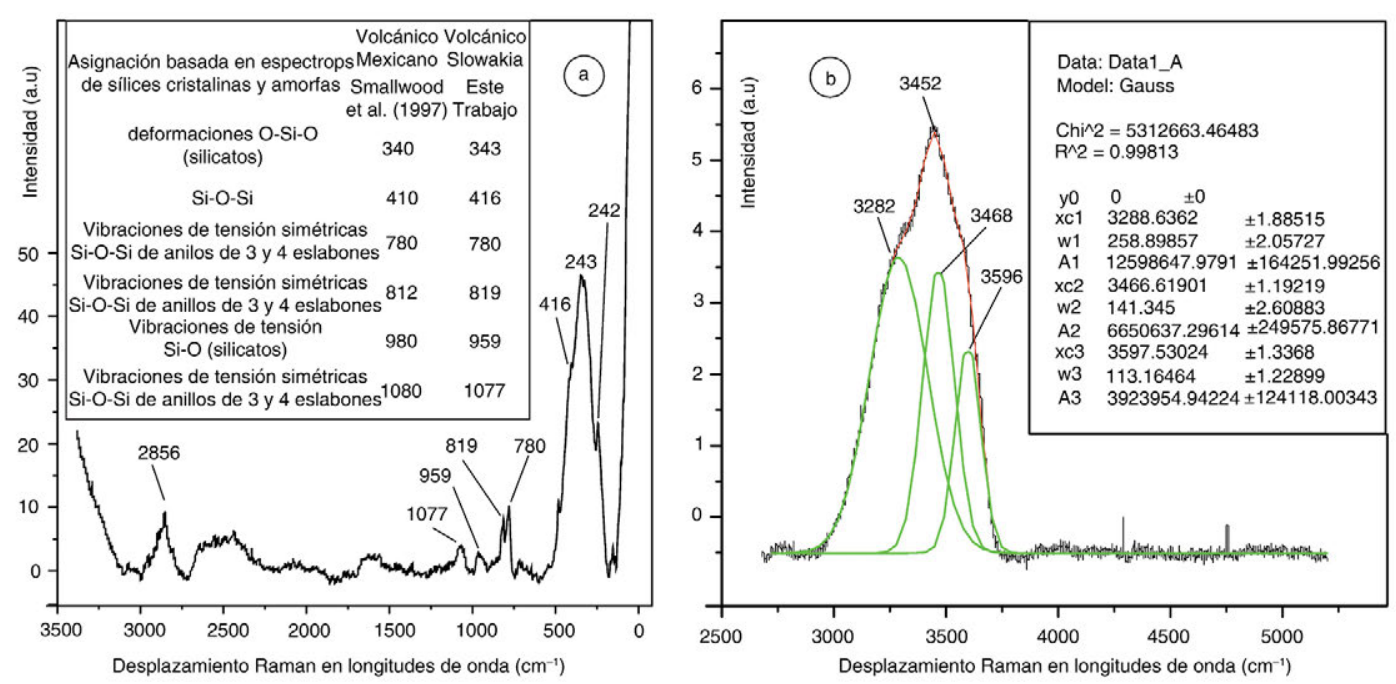

Fig. 6.-Espectro Raman del Ópalo con fuente laser a 534 nm: (a) Región espectral normal mostrando un espectro muy parecido a otros similares volcánicos de México, (b) Región espectral extendida mostrando agua molecular dentro de las lepisferas CT. 
es muy parecido a los espectros Raman de ópalos mexicanos de origen volcánico (Fig. 6a). En el espectro de la rejilla espectral ampliada (Fig. 6b), la banda característica de presencia del agua muestra una envolvente con un máximo a $3452 \mathrm{~cm}^{-1}$ junto con otros picos calculados por deconvolucion hacia los 3282,3468 y $3596 \mathrm{~cm}^{-1}$. Considerando los errores característicos de los métodos clásicos de deconvolucion de curvas por Gaussianas, es muy probable que se trate simplemente de un espectro Raman de agua líquida con modos de vibración de tensión de grupos hidroxilos, es decir con movimientos de alargamiento y compresión alternantes (tensión). Los nodos de tensión $v 1(\mathrm{OH})$ a 3233, $3393,3511,3628 \mathrm{~cm}^{-1}$ son debidos a agua dentro del ópalo (Carey, 1998). De acuerdo con otros autores, las bandas a 3410 y $3650 \mathrm{~cm}^{-1}$ están relacionadas con nodos de tensión O-H de enlaces de hidrógeno de grupos silanoles aislados (Langer \& Flörke, 1974).

\section{Tomografía computerizada de alta resolución}

La Fig. 7a representa una reconstitución tridimensional de centenares de imágenes de tomografía de rayos X de alta resolución; la representación final 3D muestra la topografía superficial en detalle. La Fig. 7b es la misma reconstitución 3D pero incluyendo detalles internos de otros materiales de

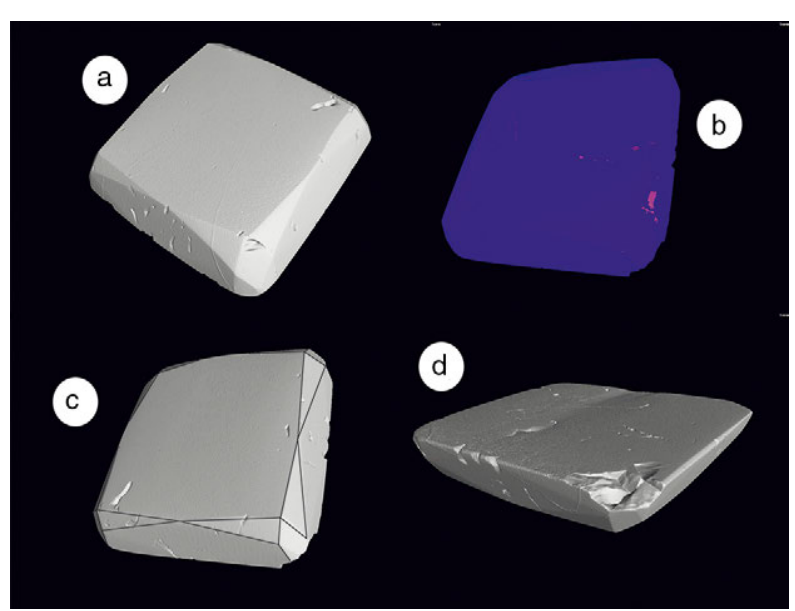

Fig. 7.- Reconstrucciones 3D de tomografía computerizada a partir de 1583 radiografías de alta resolución. (a) Superficie reconstruida mostrando la geometría externa del ópalo, (b) Geometría interna de fisuras rellenas de cloruro de plata, (c) Marcado de aristas del facetado de tipo carré-princesa, (d) Geometría externa del reverso mostrando daños de un impacto. diferente densidad, pudiendo apreciar la ubicación del cloruro de plata que rellena algunas fisuras. La Fig. 7c también es el mismo modelo 3D pero con un marcaje de aristas de las facetas para resaltar la plantilla del tallado original del ópalo en "Talla Princesa Modo Sencillo Cuadrado", que ahora podemos ver muy bien en internet-modo-imágenes incluyendo en nuestro navegador los términos ingleses gemstone-princess-cutting.

\section{Microscopía confocal perfilométrica $3 D$ de tecnología LED}

La Fig. 8a muestra la imagen escaneada de la montura de plata sobredorada por la parte trasera con una inscripción a buril que dice literalmente: "Enrique Bodson nacido en Liege lo à echo en Paris el 17 de Julio de 1772" por duplicado en francés y en castellano. La Fig. 8b es una fotografía-color 2D del detalle de la fecha 1772 obtenida con el microscopio confocal interferómetrico $3 \mathrm{D}$ de leds en la que se pueden observar algunos detalles geométricos de la fecha de grabación de la manufactura. La Fig. $8 \mathrm{c}$ es una fotografía confocal 3D sumatoria de fotos parciales obtenidas entre las cotas máxima $(+100 \mu \mathrm{m})$ y mínima $(-100 \mu \mathrm{m})$; una versión $2 \mathrm{D}$ de la Fig. anterior aparece en la Fig. 8d. La Fig. 8 e es un perfil topográfico a escala real destacando la huella del grabado de la fecha según el trazado marcado en la foto de la Fig. 8d. Por último, la Fig. $8 \mathrm{f}$ es un idealización de una herramienta o buril de grabado de metales ajustando la geometría de su cuchilla a la geometría de la huella que grabaron sobre la plata.

\section{Conclusiones}

Desde hace unos 244 años, el Museo Nacional de Ciencias Naturales de Madrid expone al público un gran ópalo noble tallado de 33 gramos engastado en montura de plata sobredorada. La pieza está bien documentada en su propia montura (año 1772), en el legajo 775 del Archivo del Museo y en la muestra 395 del catálogo de muestras de Pedro Franco Dávila con las que se fundó el propio Museo en esa fecha. El difractograma de rayos X realizado sobre el bloque de ópalo histórico es muy parecido al de otros ópalos de origen volcánico y contiene cantidades variables de cristobalita, tridimita y sílice amorfa. 


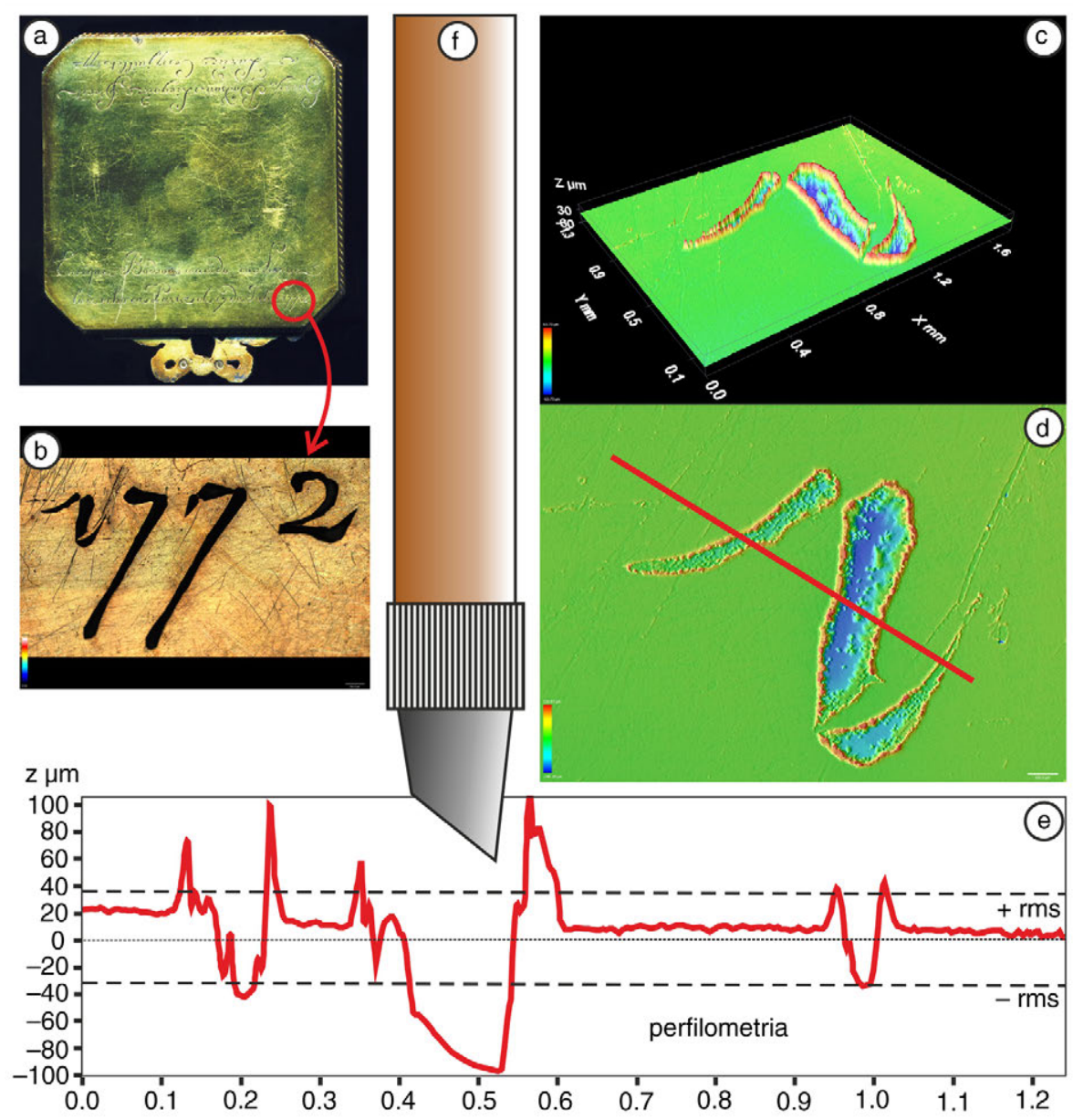

Fig. 8.-Fotografías y medidas de los grabados a buril en la montura de plata sobredorada realizadas mediante microscopía confocal perfilométrica 3D de tecnología LED. (a) Foto del anverso usando un escáner común, (b) Foto de un detalle (fecha) con la cámara del perfilómetro, (c) Reconstrucción 3D con métrica XYZ a partir de varias secciones 2D, (d) Posición "D marcando la toma de un perfil, (e) Perfil micro-topográfico, (f) Reconstrucción idealizada de la geometría del buril utilizado.

El espectro Raman muestra una banda con picos a 242,343 y $416 \mathrm{~cm}^{-1}$ asociados a deformaciones $\mathrm{O}-\mathrm{Si}-\mathrm{O}$; otra con picos a 780 y $819 \mathrm{~cm}^{-1}$ de vibraciones de tensión simétricas O-Si-O de anillos de 3 y 4 eslabones y otras menores. El espectro es similar a los de ópalos mexicanos de origen volcánico. Contiene una banda nodos de tensión $v 1$ $(\mathrm{OH})$ a $3233,3393,3511,3628 \mathrm{~cm}^{-1}$ relacionados con grupos $\mathrm{OH}$ con enlaces de hidrógeno con grupos silanoles aislados. La tomografía computerizada de rayos $\mathrm{X}$ destaca la talla cuadrada de tipo carré-princesa y los rellenos de cloruro de plata de una fisura. Bajo microscopia electrónica de barrido se observan baritinas, filoncillos de sílice enriquecida en Mn y elevados contenidos de Al y K. Estos datos junto con la información histórica sugieren que la pieza procede los yacimientos históricos de ópalos encajados en andesitas de Eslovaquia y explican la compleja óptica de la luz en el cabujón. La plata de la montura tiene mercurio y cloruro de plata que indican proceso de extracción por amalgama mercurial más un sulfuro de plata natural que provendría probablemente de las minas de Nueva España, entonces, en el año 1772, en plena producción de plata. La asociación de nuevas técnicas analíticas no-destructivas preserva la integridad de las muestras aportando datos analíticos significativos que permiten deducir procesos genéticos de minerales, procedencias y técnicas de manufactura de materiales. Todo ello facilita la caracterización, interpretación, conservación y valorización del patrimonio cultural y arqueológico. 


\section{AGRADECIMIENTOS}

El trabajo pudo ser financiado gracias al proyecto del Plan Nacional de Investigación CTM2014-55321-P.

\section{Referencias}

Alonso, P.J.; Halliburton, L.E.; Kohnke, E.E. \& Bossoli, R.B. (1983). X-ray-induced luminescence in crystalline $\mathrm{SiO}_{2}$. Journal of Applied Physics, 54: 5369-5375. http://dx.doi.org/10.1063/1.332715

Artioli, G. \& Quartieri, S. (2016). The Contribution of Geoscience to Cultural Heritage Studies. Elements, 12 (1): 13-18. http://dx.doi.org/10.2113/gselements.12.1.13

Auer, B.M. \& Skinner, J.L. (2008). IR and Raman spectra of liquid water: theory and interpretation. Journal of Chemical Physics, 128 (22): 224511. http://dx.doi. org/10.1063/1.2925258

Belem, T.; Homand-Etienne F. \& Souley M. (2000). Quantitative parameters for rock joint surface roughness. Rock Mechanics and Rock Engineering, 33 (4): 217-242. http://dx.doi.org/10.1007/s006030070001

Brewster, S.D. (1845). An account of the cause of the colors in precious opal. Journal of the Franklin Institute, 40 (3): 195. http://dx.doi.org/10.1016/0016-0032(45)90571-0

Cagnetti, A. (2009). Experimental survey on fluid brazing in ancient goldsmith's art. International Journal of Materials Research, 100 (1): 81-85. http://dx.doi. org/10.3139/146.101783

Calatayud-Arinero, M.A. (1987). Catálogo de Documentos del Real Gabinete de Historia Natural (1752-1786). CSIC, Madrid, p. 277.

Canet, C.; Camprubí, A.; González-Partida, E.; Linares, C.; Alfonso, P.; Piñeiro-Fernández, F. \& Prol-Ledesma, R.M. (2009). Mineral assemblages of the Francisco I. Madero Zn-Cu-Pb-(Ag) deposit, Zacatecas, Mexico: implications for ore deposit genesis. Ore Geology Reviews, 35 (3-4): 423-435. http://dx.doi. org/10.1016/j.oregeorev.2009.02.004

Carey, D.M. (1998). Measurement of the Raman spectrum of liquid water. Journal of Chemical Physics, 108: 2669-2675. http://dx.doi.org/10.1063/1.475659

Caucia, F.; Ghisoli, C.; Marinoni, L. \& Bordoni, V. (2013). Opal, a beautiful gem between myth and reality. Neues Jahrbuch fur Mineralogie, Abhandlungen, 190 (1): 1-9. http://dx.doi.org/10.1127/0077-7757/2012/0226

Caucia, F.; Marinoni, L.; Leone, A. \& Adamo, I. (2013). Investigation on the gemological, physical and compositional properties of some opals from Slovakia (Hungarian opals). Periodico di Mineralogia, 82 (2): 251-261. http://dx.doi.org/10.2451/2013PM0015

Crettenden, P.P.; Flintoft, M.W.; Ewen, S.J. \& Watkins, D.C. (1979). The opal industry in South Australia. Mineral Resources Review (Department of Mines, South Australia), 151: 18-29.
Chutas, N.I. \& Sack, R.O. (2004). Ore genesis at La Colorada $\mathrm{Ag}-\mathrm{Zn}-\mathrm{Pb}$ deposit in Zacatecas, Mexico. Mineralogical Magazine, 68 (6): 923-937. http://dx.doi. org/10.1180/0026461046860231

Darragh, P.J.; Gaskin, A.J.; Terrell, B.C. \& Sanders, J.V. (1966). Origin of precious opal. Nature, 209 (5018): 13-16. http://dx.doi.org/10.1038/209013a0

Demortier, G.; Fernández-Gómez, F.; Ontalba Salamanca, M.A. \& Coquay, P. (1999). PIXE in an external microbeam arrangement for the study of finely decorated tartesic gold jewellery items. Nuclear Instruments and Methods in Physics Research, Section B: Beam Interactions with Materials and Atoms, 158 (1-4): 275-280. http://dx.doi.org/10.1016/S0168-583X(99)00311-0

Dobado, R. \& Marrero G.A. (2011). The role of the Spanish imperial state in the mining-led growth of Bourbon Mexico's economy. Economic History Review, 64 (3): 855-884. http://dx.doi. org/10.1111/j.1468-0289.2010.00555.x

Fisher, J.R. (1977). Silver mines and silver miners in colonial Peru, 1776-1824. Centre for Latin American Studies, University of Liverpool, $150 \mathrm{p}$.

Franco Davila, P. (1784). A monsieur Boytet Consul General de Francia en esta corte, actualmente en Paris. Madrid a 7 de agosto de 1784. Copiador de Cartas. Legajo ${ }^{\circ} 18$, página 1. Archivo del Museo Nacional de Ciencias Naturales. Madrid.

García-Guinea, J.; Fernández-Cortés, A.; ÁlvarezGallego, M.; García-Antón, E.; Casas-Ruiz, M.; Blázquez-Pérez, D.; Teijón, O.; Cuezva, S.; Correcher, V. \& Sánchez-Moral, S. (2013). Leaching of uranyl-silica complexes from the host metapelite rock favoring high radon activity of subsoil air: Case of Castañar cave (Spain). Journal of Radioanalytical and Nuclear Chemistry, 298 (3): 1567-1585. http:// dx.doi.org/10.1007/s10967-013-2587-7

Gorton, N.T.; Walker, G. \& Burley, S.D. (1997). Experimental analysis of the composite blue cathodoluminescence emission in quartz. Journal of Luminescence, 72-74: 669-671. http://dx.doi. org/10.1016/S0022-2313(96)00242-6

Götze, J.; Plötze, M. \& Habermann, D. (2001). Origin, spectral characteristics and practical applications of the cathodoluminescence (CL) of quartz - a review. Mineralogy and Petrology, 71 (3): 225-250. http:// dx.doi.org/10.1007/s007100170040

Hachisu, S. \& Yoshimura, S. (1980). Optical demonstration of crystalline superstructures in binary mixtures of latex globules. Nature, 283 (5743): 188-189. http://dx.doi.org/10.1038/283188a0

Hsu, T.; Lucas, A. \& Pardieu, V. (2015). Splendor in the outback: A visit to Australia's opal fields. Gems \& Gemology, 51 (4): 418-427.

Ilieva, A.; Mihailova, B.; Tsintsov, Z. \& Petrov, O. (2007). Structural state of microcrystalline opals: A Raman spectroscopic study. American Mineralogist, 92 (8-9): 1325-1333. http://dx.doi.org/10.2138/am.2007.2482 
Itoh, C.; Tanimura, K. \& Itoh, N. (1988). Optical studies of self-trapped excitons in $\mathrm{SiO}_{2}$. Journal of Physics C: Solid State Physics, 21 (26): 4693-4702. http:// dx.doi.org/10.1088/0022-3719/21/26/017

Jones, C.E. \& Embree, D. (1976). Correlations of the $4.77-4.28-\mathrm{eV}$ luminescence band in silicon dioxide with the oxygen vacancy. Journal of Applied Physics, 47: 5365-5371. http://dx.doi. org/10.1063/1.322562

Jones, J.B.; Sanders, J.V. \& Segnit, E.R. (1964). Structure of opal. Nature, 204 (4962): 990-991. http://dx.doi. org/10.1038/204990a0

Jones, J.B. \& Segnit, E.R. (1971). The nature of opal I. nomenclature and constituent phases. Journal of the Geological Society of Australia, 18 (1): 57-67. http:// dx.doi.org/10.1080/00167617108728743

Kalceff, M.A.S. \& Phillips, M.R. (1995). Cathodoluminescence microcharacterization of the defect structure of quartz. Physical Review B, 52 (5): 3122-3134. http://dx.doi.org/10.1103/PhysRevB.52.3122

Ketcham, R.A. \& Carlson, W.D. (2001). Acquisition, optimization and interpretation of x-ray computed tomographic imagery: Applications to the geosciences. Computers \& Geosciences, 27 (4): 381-400. http://dx.doi.org/10.1016/S0098-3004(00)00116-3

Kita, N.T.; Ushikubo, T.; Fu, B. \& Valley, J.W. (2009). High precision SIMS oxygen isotope analysis and the effect of sample topography. Chemical Geology, 264 (1-4): 43-57. http://dx.doi.org/10.1016/j. chemgeo.2009.02.012

Krbetschek, M.R.; Götze, J.; Dietrich, A. \& Trautmann, T. (1997). Spectral information from minerals relevant for luminescence dating. Radiation Measurements, 27 (5-6): 695-748. http://dx.doi.org/10.1016/ S1350-4487(97)00223-0

Langer, K. \& Flörke O.W. (1974). Near infrared absorption spectra (4000-9000 cm-1) of opals and the role of water in these $\mathrm{SiO}_{2} \cdot \mathrm{nH}_{2} \mathrm{O}$ minerals. Fortschritte der Mineralogie, 52: 17-51.

Lee, H.S.; Park, Y.J.; Cho, T.F. \& You, K.H. (2001). Influence of asperity degradation on the mechanical behavior of rough rock joints under cyclic shear loading. International Journal of Rock Mechanics \& Mining Sciences, 38 (7): 967-980. http://dx.doi. org/10.1016/S1365-1609(01)00060-0

Luff, B.J. \& Townsend, P.D. (1990). Cathodoluminescence of synthetic quartz. Journal of Physics: Condensed Matter, 2: 8089-8097. http://dx.doi.org/10. 1088/0953-8984/2/40/009

Macdonald,R.M.(1904). Theopalformations ofAustralia. Scottish Geographical Magazine, 20 (5): 253-261. $\mathrm{http}: / /$ dx.doi.org/10.1080/14702540408554624

Mango, H.; Arehart, G.; Oreskes, N. \& Zantop, H. (2014). Origin of epithermal Ag-Au-Cu-Pb-Zn mineralization in Guanajuato, Mexico. Mineralium Deposita, 49 (1): 119-143. http://dx.doi.org/10.1007/ s00126-013-0478-z
Martini, M.; Paleari, A.; Spinolo, G. \& Vedda, A. (1995). Role of $\left[\mathrm{AlO}_{4}\right]^{0}$ centers in the 380 -nm thermoluminescence of quartz. Physical Review B, 52 (1): 138-142. http://dx.doi.org/10.1103/PhysRevB.52.138

Meixner, A.J. (2016). The Nobel Prize in Chemistry 2014 for the development of super-resolved fluorescence microscopy. Analytical \& Bioanalytical Chemistry, 407 (7): 1797-1800. http://dx.doi.org/10.1007/s002 16-014-8444-x

Moncada, D.; Mutchler, S.; Nieto, A.; Reynolds, T.J.; Rimstidt, J.D. \& Bodnar, R.J. (2012). Mineral textures and fluid inclusion petrography of the epithermal $\mathrm{Ag}-\mathrm{Au}$ deposits at Guanajuato, Mexico: Application to exploration. Journal of Geochemical Exploration, 114: 20-35. http://dx.doi.org/10.1016/j. gexplo.2011.12.001

Murali, K.V.R.M.; Naik, V.B. \& Datta, D. (2015). Gallium-nitride-based light-emitting diodes: 2014 Nobel Prize in Physics. Resonance, 20 (7): 605-616. http://dx.doi.org/10.1007/s12045-015-0219-y

Ostrooumov, M.; Fritsch, E.; Lasnier, B. \& Lefrant, S. (1999). Raman spectroscopy of opals: diagnostics and classification aids. European Journal of Mineralogy, 11 (5): 899-908. http://dx.doi.org/10.1127/ejm/ $11 / 5 / 0899$

Ponzio de Léon, C.A. (1998). Interpretación económica del último periodo colonial Mexicano. Trimestre Economico, 65 (257): 99-125.

Ramos-Arroyo, Y.R.; Prol-Ledesma, R.M.\& Siebe-Grabach, C. (2004). Características geológicas y mineralógicas e historia de extracción del Distrito de Guanajuato, México. Posibles escenarios geoquímicos para los residuos mineros. Revista Mexicana de Ciencias Geologicas, 21 (2): 268-284.

Rau, R.C. \& Amaral, E.J. (1969). Electron microscopy of precious opal. Metallography, 2 (4): 323-328. http:// dx.doi.org/10.1016/0026-0800(69)90062-7

Remond, G.; Cesbron, F.; Chapoulie, R.; Ohnenstetter, D.; Roques-Carmes, C. \& Schvoerer, M. (1992). Cathodoluminescence applied to the microcharacterization of mineral materials: A present status in experimentation and interpretation. Scanning Microscopy, 6: 23-68.

Rink, W.J.; Rendell, H.; Marseglia, E.A.; Luff, B.J. \& Townsend, P.D. (1993). Thermoluminescence spectra of igneous quartz and hydrothermal vein quartz. Physics \& Chemistry of Minerals, 20 (5): 353-361. http://dx.doi.org/10.1007/BF00215106

Rondeau, B.; Fritsch, E.; Guiraud, M. \& Renac, C. (2004). Opals from Slovakia (Hungarian opals): A re-assessment of the conditions of formation. European Journal of Mineralogy, 16: 789-799. http://dx. doi.org/10.1127/0935-1221/2004/0016-0789

Sanders, J.V. (1964). Colour of precious opal. Nature, 204 (4964): 1151-1153. http://dx.doi.org/10.1038/ 2041151a0 
Sanders, J.V. \& Murray, M.J. (1978). Ordered arrangements of spheres of two different sizes in opal. Nature, 275 (5677): 201-203. http://dx.doi.org/10.1038/275201a0

Sigel Jr, G.H. \& Marrone, M.J. (1981). Photoluminescence in as-drawn and irradiated silica optical fibers: an assessment of the role of non-bridging oxygen defect centers. Journal of Non-Crystalline Solids, 45 (2): 235-247. http://dx.doi.org/10.1016/0022-3093(81)90190-3

Smallwood, A.G.; Thomas, P.S. \& Ray, A.S. (1997). Characterisation of sedimentary opals by Fourier transform Raman spectroscopy. Spectrochimica Acta - Part A: Molecular \& Biomolecular Spectroscopy, 53 (13): 2341-2345. http://dx.doi.org/10.1016/ S1386-1425(97)00174-1

Spooner, N.A. \& Questiaux, D.G. (2000). Kinetics of red, blue and UV thermoluminescence and optically-stimulated luminescence from quartz. Radiation Measurements, 32 (5-6): 659-666. http://dx.doi. org/10.1016/S1350-4487(00)00067-6

Stevens-Kalceff, M.A. (2009). Cathodoluminescence microcharacterization of point defects in $\alpha$-quartz.
Mineralogical Magazine, 73 (4): 585-605. http://dx. doi.org/10.1180/minmag.2009.073.4.585

Stevens-Kalceff, M.A. (2013). Cathodoluminescence microanalysis of silica and amorphized quartz. Mineralogy and Petrology, 107 (3): 455-469. http:// dx.doi.org/10.1007/s00710-013-0275-5

Sun, Q. (2009). The Raman OH stretching bands of liquid water. Vibrational Spectroscopy, 51 (2): 213-217. http://dx.doi.org/10.1016/j.vibspec.2009.05.002

Tamla, Ü. \& Varkki, H. (2009). Learning the technologies of making beaded wire. Estonian Journal of Archaeology, 13 (1): 36-52. http://dx.doi.org/10.3176/arch. 2009.1.03

Walrafen, G.E.; Fisher, M.R.; Hokmabadi, M.S. \& Yang, W.H. (1986). Temperature dependence of the low- and high-frequency Raman scattering from liquid water. The Journal of Chemical Physics, 85: 6970-6982. http://dx.doi.org/10.1063/1.451384

Wellington, S.L. \& Vinegar, H.J. (1987). X-Ray Computerized Tomography. Journal of Petroleum Technology, 39 (8): 885-898. http://dx.doi.org/10.2118/16983-PA 